\title{
Outpatient management or hospitalization of patients with proven or suspected SARS-CoV-2 infection: The HOME-CoV rule.
}

Douillet D. ( $\sim$ Delphine.Douillet@chu-angers.fr)

CHU ANGERS

Mahieu R.

CHU ANGERS

Boiveau V.

CHU Angers

Vandamme Y.-M.

CHU ANGERS

Armand $\mathrm{A}$.

CHU ANGERS

Morin F.

CHU ANGERS

Savary D.

CHU ANGERS

Dubée V.

CHU ANGERS

Annweiler C.

CHU ANGERS

Roy P.-M.

CHU ANGERS

\section{Research Article}

Keywords: covid-19; hospitalization; outpatient; Delphi method; expert consensus, rule-based decisionmaking.

Posted Date: June 5th, 2020

DOI: https://doi.org/10.21203/rs.3.rs-33362/v1

License: (c) (1) This work is licensed under a Creative Commons Attribution 4.0 International License.

Read Full License 


\section{Abstract}

In the context of the COVID-19 pandemic and overloaded hospitals, a central issue is the need to define reliable and consensual criteria for hospitalization or outpatient management in mild cases of COVID19. Our aim was to define an easy-to-use clinical rule aiming to help emergency physicians in hospitalization or outpatient management decision-making for patients with suspected or confirmed SARS-CoV-2 infection (the HOME-CoV Rule). The Delphi method was used to reach a consensus of a large panel of 51 experts: emergency physicians, geriatricians, infectious disease specialists, and ethical consultants. A preliminary list of eligible criteria was compiled based on a literature review. Four rounds of anonymized expert consultations were performed. The experts were asked to score each item as relevant, possibly relevant and non-relevant, as major or minor, and to choose the cut-off. They were also able make suggestions and remarks. Eight criteria constituting the HOME-CoV were selected: six correspond to the severity of clinical signs, one to the clinical course (clinically significant worsening within the last 24 hours), and the last corresponds to the association of a severe comorbidity and an inadequate living context. Hospitalization is deemed necessary if a patient meets one or more of the criteria. In the end, $94.4 \%$ of the experts agreed with the defined rule. Thanks to the Delphi method, an absolute consensus was obtained of a large panel of experts on the HOME-CoV rule, a decision-making support mechanism for clinicians to target patients with suspected or confirmed COVID-19 requiring hospitalization.

\section{Trial registration: NCT04338841}

\section{Introduction}

The novel coronavirus (SARS-CoV-2) has spread worldwide and thecoronavirus disease (COVID-19) is responsible of more than 2,5million cases globally (04/23/2020) [1]. The classification ofCOVID-19 as a pandemic by the World Health Organization on 11 March2020 alerted every country-specific health care system to the needfor an urgent response to the requirements and challenges of thisunprecedented situation. Because the spectrum of forms of thedisease varies from asymptomatic to severe, public health systemshave been mobilized at all levels [2]. Most cases during theoutbreak of COVID-19 in China were reported by the Chinese Centerfor Disease Control and Prevention (CDC) team in a large cohort of 72,314 patients and $81 \%$ were classified as mild (non-pneumonia andmild pneumonia) and $14 \%$ were severe [3]. There is growing concernthat the healthcare system, and intensive care units (ICU) andemergency departments (ED) in particular, will not be able to copewith the scale of the outbreak. Many models have predicted demandwould rapidly exceed hospital capacities in most countries [46].The excessive hospitalization of patients with only mild symptomsmay lead to overloaded hospitals. In this context, the decisionbetween hospitalization or outpatient management in cases of mildCOVID-19 in ED is crucial. 
In pneumonia patients or in patients with sepsis, many riskassessment score matrices and decisionmaking tools, such as thePulmonary Severity Index (PSI), CRB 65, CURB65, sequential organfailure assessment (SOFA) and quick sequential organ failureassessment (qSOFA), exist to identify low-risk patients [7-10]. However, most of them cannot be used to quickly identify low-riskpatients in ED because they incorporate biological or imagingparameters (PSI, CURB-65, SOFA). In addition, they do not integrateall pragmatic elements that are taken into account in anorientation decision such as decompensated comorbidity or inabilityto take medication or inadequate follow-up care once the patienthas been discharged.

Our aim was to define an easy-to-use clinical rule aiming tohelp emergency physicians decide between hospitalization oroutpatient management for patients with suspected or confirmedSARS-CoV-2 infection (the HOME-CoV Rule:Hospitalization or OutpatientManagEment of patients withSARS-CoV-2 infection).

\section{Methods}

A Delphi method was used to develop a list of items that willconstitute the HOME-CoV rule. In short, the Delphi method consistsof a multiple-round questionnaire sent to a panel of experts who,through participating in a series of rounds, collectively identifyrelevant candidate items [11]. After each round, the experts aregiven results of the group trends and are asked to reconsider theirinitial opinion for items with low agreements $(<75 \%)$ in thelight of these trends. A consensus for decision making is usuallyobtained by four rounds. We used an electronical survey through thebuilt-in tools GoogleForms ${ }^{\circledR}$ website with the aim to finish theprocess in less than two weeks.

\section{Preliminary phase}

The main investigators (DD, RM and PMR) began by reviewing theliterature on the characteristics of COVID-19 patients at high riskof progression to a severe illness. Because of the limitedpublished data, pre-print studies were also considered. Apreliminary list of pre-existing conditions and clinicalcharacteristics associated with a greater risk of diseaseprogression to a severe illness was defined by the study'sscientific committee composed of 7 experts in emergency medicine,infectious diseases, geriatrics, and ethics. The preliminary listincluded 10 clinical and disease course criteria, 22 comorbiditiesand treatments, and 3 living conditions (table 1). 
Preliminary list of criteria

\begin{tabular}{|c|c|c|c|c|}
\hline & \multicolumn{4}{|c|}{ Thresholdvalue } \\
\hline \multicolumn{5}{|l|}{$\begin{array}{l}\text { characteristics and } \\
\text { ourse }\end{array}$} \\
\hline oryrate & $\geq 22 / \min$ & $\geq 25 / \min$ & $\geq 30 / \min$ & \\
\hline al oxygensaturation & $\leq 90 \%$ & $\leq 92 \%$ & $\leq 94 \%$ & \\
\hline $\begin{array}{l}\text { talk without stopping } \\
\text { th }\end{array}$ & $<5$ sec & $<8$ sec & $<10$ sec & \\
\hline ssure & $\begin{array}{c}\text { SystolicBP } \leq \\
100 \mathrm{mmHg}\end{array}$ & $\begin{array}{c}\text { SystolicBP } \leq \\
90 \mathrm{mmHg}\end{array}$ & $\begin{array}{c}\text { SystolicBP } \leq 90 \mathrm{mmHg} \\
\& \text { diastolic } \mathrm{BP} \leq \\
60 \mathrm{mmHg}\end{array}$ & \\
\hline $\mathrm{e}$ & $\geq 110 \mathrm{bpm}$ & $\geq 120 \mathrm{bpm}$ & $\geq 125 \mathrm{bpm}$ & \\
\hline $\begin{array}{ll}\mathrm{n} & \text { or } \\
\text { consciousness } & \end{array}$ & NA & & & \\
\hline mia & $\leq 35^{\circ} \mathrm{C}$ & $\leq 36^{\circ} \mathrm{C}$ & & \\
\hline rmia & $\geq 39^{\circ} \mathrm{C}$ & $\geq 40^{\circ} \mathrm{C}$ & $\geq 41^{\circ} \mathrm{C}$ & \\
\hline $\begin{array}{l}\text { significant worsening } \\
\text { elast } 24 \text { hours. }\end{array}$ & NA & & & \\
\hline $\begin{array}{l}\text { the onset of initial } \\
\mathrm{s} \text { and admission } \\
7 \text { days to } 10 \text { days }\end{array}$ & - & - & - & - \\
\hline \multicolumn{5}{|l|}{ dities } \\
\hline & $\geq 65 y^{*}$ & $\geq 70 y^{*}$ & $\geq 75 y^{*}$ & $\geq 80 y^{*}$ \\
\hline is Index & $\geq 30 \mathrm{~kg} / \mathrm{m}^{2}$ & $\geq 35 \mathrm{~kg} / \mathrm{m}^{2}$ & $\geq 40 \mathrm{~kg} / \mathrm{m}^{2}$ & \\
\hline \multirow[t]{2}{*}{ disorder } & mild & moderate & severe & - \\
\hline & Anystage & StageIII/IV & - & - \\
\hline \multirow[t]{2}{*}{$\begin{array}{lcc}\text { ory } & \text { failure } & \text { with } \\
\text { us oxygentherapy } & \end{array}$} & - & - & - & - \\
\hline & Anystage & $\begin{array}{c}\text { Controlled with } \\
\text { systemic } \\
\text { glucocorticoidtherapy }\end{array}$ & unstable & - \\
\hline enal failure & $\begin{array}{c}\text { Moderate }(\mathrm{GFR}<60 \\
\mathrm{mL} / \mathrm{min})\end{array}$ & $\begin{array}{c}\text { Severe }(\mathrm{DFG}< \\
30 \mathrm{ml} / \mathrm{min})\end{array}$ & Terminal & dialysis \\
\hline ; & Anystage & StageChild B or C & StageChild C & - \\
\hline eart failure & Anystage & NYHA $\geq$ III & - & - \\
\hline \multirow[t]{2}{*}{ ypertension } & - & - & - & - \\
\hline & - & - & - & - \\
\hline
\end{tabular}




\begin{tabular}{|c|c|c|c|c|}
\hline sculardisease & - & - & - & \\
\hline rartery disease & - & - & - & - \\
\hline history of VTE† & - & - & - & - \\
\hline $\mathrm{a}$ & Historyof cancer & Activecancer & $\begin{array}{l}\text { Cancerreceiving } \\
\text { chemotherapy }\end{array}$ & - \\
\hline amunodeficiency Virus & Historyof HIV & UncontrolledHIV & - & - \\
\hline mmunodeficiency & - & & - & \\
\hline sy & Anyterm & 3rdtrimester & - & - \\
\hline itor or $A R B$ & - & - & - & - \\
\hline $\begin{array}{ll}\text { lidal } & \text { anti- } \\
\text { itorydrug }\end{array}$ & - & - & - & \\
\hline glucocorticoid therapy & Anydosage & Dosage $>10 \mathrm{mg} / \mathrm{d}$ & & \\
\hline uppressivedrug & - & - & - & - \\
\hline \multicolumn{5}{|l|}{ aditions } \\
\hline $\begin{array}{lr}\text { riate } & \text { dwelling } \\
\text { is, } & \text { frailrelative at } \\
& \text { long-term } \\
\text { tution) } & \end{array}$ & - & - & - & - \\
\hline $\begin{array}{l}\text { upport person (family } \\
\text { orfriend) }\end{array}$ & - & - & - & \\
\hline $\begin{array}{l}\text { low-up impossible (no } \\
\text { oractitioner, telephone } \\
\text { tt possible, etc.) }\end{array}$ & - & - & - & \\
\hline
\end{tabular}

*y : years †VTE: Venous Thrombo-Embolism

\section{Delphi Panel}

An invitation to participate to the Delphi method was sent to 64French and Belgian physicians working in ED, infectious diseasesdepartments, ICU and geriatric medicine and two experts in ethics. They were selected according to their clinical experience inrule-based decision-making and their interest in the field ofCOVID-19. The main investigators were not included in the panel ofexperts for the subsequent Delphi method questionnaire. The expertswere asked to respond to each item in regard to the purpose of theHOME-CoV rule.

\section{Data collection}


The four-round Delphi method took place between April 4 andApril 16, 2020. Experts were asked to rate each criterion for itsrelevance (relevant, possibly relevant, non-relevant), for the bestcut-off value (1 to 4 proposed cut-off value if applicable) and forits level of significance (major or minor criteria) (table 1). Onemajor criterion or two combined minor criteria will requirehospitalization.

For the first round, a questionnaire was sent through anelectronic survey with the preliminary list of criteria selected bythe scientific committee. The experts were asked to score each iteminto 3 categories of relevance (relevant, possibly relevant, andnon-relevant) and 2 categories of significance (major or minor).For non-binary items (ordinal or continuous variables), the expertshad to select a "cut-off value" among 1 to 4 proposals sourced fromresearch literature. They could also propose additional criteria orother cut-off values and make anonymous comments. The duration ofeach round was 72 hours with an electronic reminder every 24 hours. The results were analyzed by the main investigators, with detailsof the experts who made suggestions or comments anonymized. At theend of the first and the second rounds, items considered asrelevant with a strong agreement between experts ( $\geq 75 \%$ ) wereselected and incorporated in the rule. Items considered asnon-relevant or facultative by $75 \%$ of the experts were excluded.The same rule was applied to consider each item as major or minorand to define the cut-off. Values that achieved an agreement $\geq 75 \%$ were selected. Criteria that did not fulfill these conditions weresubjected to the next round. On the basis of the comments of theexperts, the main investigators proposed some groupings and/orclarifications and submitted them to the experts again.

In the second round, the experts were asked to reconsider theiropinions and to score the new proposals taking into account theresults of the last step, the group trends, and the anonymizedcomments of the others.

In the third round, the option "possibly relevant" was removedas well as the cut-off value with the lowest agreement for thoseitems concerned. The experts were so asked to make a choice betweenonly two options for the remaining criteria: relevant ornon-relevant; major or minor; cut-off 1 or cut-off 2.

Finally, in the last round, the experts were asked to validateor reject the overall criteria constituting the HOME-CoV rule.

\section{Ethics}

This research project is part of an important trial thatobtained approval from the Comite de Protection des PersonnesOuest IV - Nantes on $4^{\text {th }}$ March 2020 (36/20_2). Thesponsor of the study is CHU d'Angers (Angers University Hospital),Delegation for Clinical Research and Innovation. Approval for thisstudy was obtained from all participants who gave their writteninformed consent.

\section{Results}

Among the 64 who were approached to participate, 51 expertsagreed (80\%). Among them, 47 experts participated in the first andthe second rounds (92\%), 42 (82\%) in the third, and $37(72.5 \%)$ inthe fourth 
round of the Delphi method.

In the first round, among the 35 items of the preliminary list,seven items were classified as relevant (i.e. respiratory rate,peripheral capillary oxygen saturation, ability to speak, bloodpressure, consciousness or confusion, home follow-up impossible,and clinically significant worsening within 24 hours). Twelve itemswere rejected. Details, and particularly those pertaining to theclassification as major or minor and the cut-off values, arementioned (Supplementary Table 1).

In the second round, 18 unclassified items were proposed to theexperts and 3 more items were classified as relevant (i.e. chronicsevere respiratory disease, inappropriate dwelling in whichcontainment is complicated, and lack of support person), and 3items were rejected (Supplementary Table 2).

\begin{tabular}{|l|}
\hline Table 2 . HOME-CoV rule \\
Respiratory rate $\geq 25 / \mathrm{min}$ \\
Abilityto talk without breathing $<8 \mathrm{sec}$ \\
Systolicblood pressure $\leq 90 \mathrm{mmHg}$ \\
Heartrate $\geq 120$ beats/min \\
Confusion or impairedconsciousness \\
Clinically significant worsening within thelast 24 hours \\
Severe comorbidity ${ }^{*}$ AND inadequate livingconditions ${ }^{\dagger}$
\end{tabular}

\footnotetext{
* Severe chronic respiratory disease (unstable asthma, COPD stageIII or IV, respiratory failure with continuous oxygen therapy), chronic heart failure (NYHA $\geq$ III), severe cognitive disorder, orimmunodepression (primary immunodeficiency, uncontrolled HIV,immunosuppressive drug, chemotherapy)

${ }^{\dagger}$ Inappropriate dwelling (homeless, frailrelative at home, long term care institution), lack of supportperson (family member or friend), or home follow-upimpossible.
}

In the third round all remaining items were classified: 3 asrelevant (i.e. severe cognitive disorder, chronic heart failure,and immunodepression); and 1 was rejected. Grouping severecomorbidity and inadequate living conditions together in onecriterion was proposed. Severe comorbidity includes severe chronicrespiratory disease (unstable asthma, chronic obstructive pulmonarydisease (COPD) stage III or IV, and respiratory failure withcontinuous oxygen therapy), chronic heart failure (NYHA $\geq I I I)$,severe cognitive disorder, or immunodepression (primaryimmunodeficiency, uncontrolled HIV, immunosuppressive drug, orchemotherapy). Inadequate living conditions include inappropriatedwelling (homeless, frail relative at home, long term careinstitution), lack of support person (family member or friend), orhome follow-up impossible (Supplementary Table 3). 
The final rule includes 8 criteria: 6 items correspond toclinical signs of severity, 1 to the disease course and the last 1 to the association of a severe comorbidity and an inappropriateliving condition. (table 2). The presence of one or more criteriashould lead the physician to consider hospitalization.

In the last round, the final HOME-CoV rule was submitted to theexperts and achieved an agreement of $94.4 \%$ of the experts $(n=34 / 36)$.

\section{Discussion}

Using a Delphi method, the panel of 51 experts designed theHOME-CoV rule based on 8 clinical criteria to help physiciansdecide between hospitalizing patients with mild COVID-19 symptomsor treating them as outpatients. Hospitalization is deemednecessary if a patient with COVID-19 meets one or more criteriaconsisting of 6 major clinical signs, has experienced clinicallysignificant worsening within the last 24 hours, or has a severecomorbidity and inadequate living conditions. Conversely, when nocriteria of the rule are met, outpatient management should beconsidered. For example, a 54-year-old man presenting to the EDwith symptoms consistent with COVID-19 (ageusia, myalgia, andfever) and unable to speak or to count without taking a breath morethan 6 seconds should need hospitalization. A 78-year-old womanwith chronic heart failure (NYHA III) presenting mild dyspnea butno desaturation or other clinical signs of severity and who liveswith her husband in a reassuring environment can be treated on anoutpatient basis with instructions on warning signs to watch.

Due to the rapid spread of the novel coronavirus SARS-CoV-2, nohigh-grade recommendation is yet available for management ofCOVID-19 patients. Most guidelines are based on expert opinion witha very low certainty of evidence. Almost all suggest that thedecision to manage a patient as an inpatient or an outpatientshould be made on a case-by-case basis or recommend applying atriage tool all the while without specifying which one to use[12-14]. SOFA score on admission, age, gender, d-dimer, serumlactate dehydrogenase, C-reactive protein level, the coefficient ofvariation of red blood cell distribution width, lymphocyte count,blood urea nitrogen, direct bilirubin, albumin, and quantitativeevaluation on CT scan have all been associated with severe forms ofCOVID-19 and mortality [3, 15-19]. However, these risk factors wereidentified in cohorts of patients with COVID-19 who had beenhospitalized and none of them has been evaluated to guide themanagement of suspected COVID-19 patients on admission in the ED.Moreover, like most previous risk assessment scores for sepsis orpneumonia incorporating biological or imaging parameters, theycannot be used to quickly identify low-risk patients in ED[7-9].

The best methodology for developing a decision rule is toperform multivariate logistic regression on a derivation importantcohort of patients and to validate the rule in another importantcohort. This was not possible for our purpose in lack of large databasis of COVID-19 patients including patients hospitalized as wellas patients managed at home. The Delphi method is widely used toprovide an expert consensus based on available data and expertexperiences through a multiple-round questionnaire [20]. Thismethod is recommended when scientific data are limited. Forexample, it has been previously used for building SEPSIS-3consensus, for the definition of appropriate management ofoutpatient parenteral antimicrobial 
therapy, and for elaborating aconsensual definition of de-escalation of beta-lactams [21-23]. Theuse of an Internet-based version of the Delphi process allowed usto complete the fourth round in less than two weeks. This"electronic Delphi" method was motivated by the sanitary context ofcontainment and the urgent need for COVID-19 management guidelineswhile allowing for the recruitment of a large panel of experts.Despite the exceptional sanitary situation, the high level ofparticipation and the almost absolute expert consensus on the finalrule (94.4\%) are a pledge of quality and may assure a high level ofacceptance of this guideline by physicians.

The HOME-CoV rule incorporates 6 major clinical signs, 3concerning respiratory status, 2 hemodynamic status, and oneneurological status. Most of them were taken into account inprevious severity rules for sepsis and/or pneumonia (respiratoryrate, pulse oxygen saturation, systolic blood pressure, heart rate,confusion, or impaired consciousness). Nevertheless, the cut-offswere debated between experts. Most of the time, the consensus wasreached on an attitude that should be adopted with care with theaim to apply the rule as a guide for the majority of patients butnot as an absolute decision-making rule. For example, $\mathrm{SpO}_{2}$ at $94 \%$ in ambient air is a severity criterion for ayoung person without comorbidity but may be a usual feature for anold person or a patient with chronic respiratory disease. Thecut-off for the respiratory rate decided upon ( $\geq 25 / \mathrm{min}$ ) may appearas a mid-mid choice in comparison to other rules $[7,9,21]$. However,it corresponds to the value found in the epidemiological study ofCOVID-19 patients in China [17]. The ability to talk or to countwithout breathing is a less common criterion but currently used inthe unformal assessment of dyspneic patients [24,25]. By defining 8seconds as the time cut-off, the HOME-CoV rule proposes astandardization of this criterion. From the outset, the expertsconsidered a clinically significant worsening within the last 24 hours to be a major criterion. This criterion may appear, at leastpartly, subjective. However, the clinical course of COVID-19 may bea good indicator of the shortterm risk of complication, as rapidprogressions to severe hypoxemia have been observed [26].

The HOME-CoV rule may be an important help decision making forphysicians. Faced with a lack of reliable criteria andrecommendations, physicians use their individual gestalt perceptionto decide whom to hospitalize or to manage as an outpatient.However, gestalt evaluation is associated with a great variabilityamong physicians and an overestimation of patients' short-term riskof adverse outcome [27, 28]. In the specific field of the COVID-19pandemic, gestalt accuracy may be even lower than expected in othercircumstances and hospitalizing patients when there is "any concernfor rapid deterioration or an inability to return promptly tohospital" may underestimate the number of patients who can bemanaged at home and lead to hospitals becoming overcrowded. Indeed,among 1,099 patients hospitalized in China for COVID-19, 6.1\%required mechanical ventilation and $41.3 \%$ needed oxygen therapy,indicating that a significant proportion would not have requiredspecific in-hospital care [2]. In cases of pneumonia, the use of aclinical prediction rule has been proven to improve theidentification of low-risk patients, to increase the rate ofpatients managed at home, and to reduce costs of medical care $[27,28]$. At least the same benefit could be expected as a result ofdeploying the HOME-CoV rule in ED. This rule could be also usefulfor general practitioners and physicians in older nursing home. 
Nevertheless, our study has some limitations. Most of theexperts consulted were French and their personal experiences inCOVID-19 management were recent and varied. The rule does not applyto patients with rare and/or very specific comorbidity or inspecific clinical situations. It does not take into account somecriteria that appear, in recent data, to be death risk factors forSARS-CoV-2 infection, such as obesity, diabetes, and hypertension[29-30]. Indeed, the real direct impact of these factors is stillunknown, as there has still been no large-scale internationalepidemiological study providing multivariate analysis of allpossible risk factors. The decision of the expert panel mayfacilitate the deployment of the rule in many countries and forother viral pneumonia. Finally, in the absence of systematicscreening, the rule may only apply to symptomatic patients for whomthe search for infection has been carried out in the ED or prior toadmission, and not to all asymptomatic patients or those withoutsuggestive symptoms.

The HOME-CoV rule achieved by a Delphi method provides aneasy-to-use clinical tool for physicians in deciding betweenhospitalization or outpatient management for patients withsuspected or confirmed SARS-CoV-2 infection.

\section{Declarations}

\section{Declaration of interests}

We declare no conflicts of interest.

\section{HOME-CoV scientific committeeand expert group}

- Andrianjafy H., Emergency Department, GH Nord-Essonne,Longjumeau, France.

- Annweiler C., Geriatric Department, CHU Angers, Angers,France.

- Armand A., Emergency Department, CHU Angers, Angers,France.

- Baudin L., Emergency Department, CH Cholet, Cholet,France.

- Bekhir L., Emergency Department, Cliniques universitairessaint Luc, Bruxelles, Belgium.

- Benezit F., Department of infectious disease, CHU Rennes,Rennes, France.

- Benhammouda K., Emergency Department, CH Colmar, Colmar,France.

- Bissolokele P., Emergency Department, CH Libourne, Libourne,France.

- Blanchi S., Department of infectious disease, CH Le Mans, LeMans, France.

- Boiveau V., Emergency Department, CHU Angers, Angers,France.

- Bouiller K., Department of infectious disease, CHU Besançon,Besançon, France. 
- Bouillon J.-B., Emergency Department, CHU Clermont Ferrand,Clermont Ferrand, France.

- Brice C., Emergency Department, CH Saint Brieuc, Saint Brieuc,France.

- Brunel A.-S., Department of infectious disease, CHU Besançon,Besançon, France.

- Cayeux C., Emergency Department, CH Remiremont, Remiremont,France.

- Cazenave B., Department of infectious disease, GHTYvelines-Nord, Saint Germain en Laye, France.

- Chauvin A., Emergency Department, APHP - Hôpital Lariboisière,Paris, France.

- Claessens YE., Emergency Department, Princess Grace Hospital,Monte Carlo, Monaco.

- Cormier H., Department of infectious disease, CHU Angers,Angers, France.

- Coustilleres F., Department of infectious disease, CHU Tours, Tours, France.

- Crochette N., Department of infectious disease, CH Le Mans, LeMans, France.

- Dall Acqua D., Emergency Department, CH Vichy, Vichy,France.

- Douillet D., Emergency Department, CHU Angers, Angers,France.

- Dupriez F., Emergency Department, Cliniques universitairessaint Luc, Bruxelles, Belgium.

- Friou E., Emergency Department, CHU Angers, Angers,France.

- Gangloff C., Emergency Department, CHU Rennes, Rennes,France.

- Gennai S., Emergency Department, CHU Reims, Reims, France.

- Joly L.-M., Emergency Department, CHU Rouen, Rouen,France.

- Karam H.-H., Emergency Department, CHU Limoges, Limoges,France.

- Le Bot A., Department of infectious disease, CHU Rennes,Rennes, France.

- Lemaignen A., Department of infectious disease, CHU Tours,Tours, France.

- Leroy A., Emergency Department, CH Troyes, Troyes, France.

- Mahieu R., Department of infectious disease, CHU Angers,Angers, France.

- Marchant N., Emergency Department, CH Alpes Lemant, Contaminesur Avre, France.

- Marjanovic N., Emergency Department, CHU Poitiers, Poitiers,France. 
- Montassier E., Emergency Department, CHU Nantes, Nantes,France.

- Morin F., Emergency Department, CHU Angers, Angers,France.

- Pasquier J., Department of infectious disease, CHU Martinique,Martinique, France.

- Patrat Delon S., Department of infectious disease, CHU Rennes, Rennes, France.

- Penaloza Baeza A., Emergency Department, Cliniquesuniversitaires saint Luc, Bruxelles, Belgium.

- Plantefeve G., Emergency Department, CH Argenteuil,Argenteuil, France.

- Roy P.-M., Emergency Department, CHU Angers, Angers,France.

- Sanderink D., Department of infectious disease, CHU Angers,Angers, France.

- Savary D., Emergency Department, CHU Angers, Angers,France.

- Schmidt J., Emergency Department, CHU Clermont Ferrand,Clermont Ferrand, France.

- Schotte T., Emergency Department, CH Le Mans, Le Mans,France.

- Soulie C., Emergency Department, CH Cholet, Cholet,France.

- Tchangai-Kao S., Department of infectious disease, CH SaintNazaire, Saint Nazaire, France.

- Thiebaud P.-C., Emergency Department, APHP-Hôpital SaintAntoine, Paris, France.

- Timsit E., Emergency Department, CHU Dijon, Dijon, France.

- Trabattoni E., Emergency Department, APHP - Hôpital saintJoseph, Paris, France.

- Turmel J.-M., Department of infectious disease, CHUMartinique, Martinique, France.

- Vandamme Y.-M., Department of infectious disease, CHU Angers,Angers, France.

- Violeau M., Emergency Department, CH Niort, Niort, France.

- Yombi J.-C., Department of infectious disease, Cliniquesuniversitaires saint Luc, Bruxelles, Belgium.

\section{References}

1. WHO situation reports. Novel Coronavirus (2019-nCoV) situationreports. Available at:https://www.who.int/emergencies/diseases/novel-coronavirus-2019/situation-reports.Accessed 17 April 2020. 
2. Guan W-J, Ni Z-Y, Hu Y, et al. Clinical Characteristics ofCoronavirus Disease 2019 in China. N Engl J Med2020;

3. Wu Z, McGoogan JM. Characteristics of and Important LessonsFrom the Coronavirus Disease 2019 (COVID-19) Outbreak in China:Summary of a Report of 72314 Cases From the Chinese Center forDisease Control and Prevention. JAMA 2020;

4. Massonnaud C, Roux J, Crépey P. COVID-19: Forecasting shortterm hospital needs in France. medRxiv 2020;:2020.03.16.20036939.

5. Remuzzi A, Remuzzi G. COVID-19 and Italy: what next? Lancet2020;

6. Gilbert M, Pullano G, Pinotti F, et al. Preparedness andvulnerability of African countries against importations ofCOVID-19: a modelling study. Lancet 2020;395:871-877.

7. Fine MJ, Auble TE, Yealy DM, et al. A prediction rule toidentify low-risk patients with communityacquired pneumonia. NEngl J Med 1997; 336:243-250.

8. Marti C, Garin N, Grosgurin O, et al. Prediction of severecommunity-acquired pneumonia: a systematic review andmeta-analysis. Crit Care 2012; 16:R141.

9. Aujesky D, Auble TE, Yealy DM, et al. Prospective comparison ofthree validated prediction rules for prognosis incommunity-acquired pneumonia. Am J Med 2005;118:384-392.

10. Vincent JL, Moreno R, Takala J, et al. The SOFA (Sepsis-relatedOrgan Failure Assessment) score to describe organdysfunction/failure. On behalf of the Working Group onSepsis-Related Problems of the European Society of Intensive CareMedicine. Intensive Care Med 1996;22:707-710.

11. Kötter T, Blozik E, Scherer M. Methods for the guideline-baseddevelopment of quality indicators-a systematic review. ImplementSci 2012; 7:21.

12. Infectious Diseases Society of America Guidelines on theTreatment and Management of Patients with COVID-19. Available at:https://www.idsociety.org/practice-guideline/covid-19-guidelinetreatment-and-management/.Accessed 17 April 2020.

13. Canada PHA of. Clinical Management of Patients with Moderate toSevere COVID-19 - Interim Guidance. 2020. Available at:https://www.canada.ca/en/public-health/services/diseases/2019novel-coronavirus-infection/clinical-management-covid-19.html.Accessed 17 April 2020.

14. CDC. Coronavirus Disease 2019 (COVID-19). 2020. Available at:https://www.cdc.gov/coronavirus/2019-ncov/hcp/clinical-guidance-managementpatients.html.Accessed 21 April 2020.

15. Ji D, Zhang D, Xu J, et al. Prediction for Progression Risk inPatients with COVID-19 Pneumonia: the CALL Score. Clin Infect Dis2020;

16. Gong J, Ou J, Qiu X, et al. A Tool to Early Predict SevereCorona Virus Disease 2019 (COVID-19) : A Multicenter Study usingthe Risk Nomogram in Wuhan and Guangdong, China. Clin Infect Dis2020;

17. Zhou F, Yu T, Du R, et al. Clinical course and risk factors formortality of adult inpatients with COVID19 in Wuhan, China: aretrospective cohort study. Lancet 2020; 
18. Mo P, Xing Y, Xiao Y, et al. Clinical characteristics ofrefractory COVID-19 pneumonia in Wuhan, China. Clin Infect Dis2020;

19. Li K, Fang Y, Li W, et al. CT image visual quantitativeevaluation and clinical classification of coronavirus disease(COVID-19). Eur Radiol 2020;

20. Diamond IR, Grant RC, Feldman BM, et al. Defining consensus: asystematic review recommends methodologic criteria for reporting ofDelphi studies. J Clin Epidemiol 2014;67:401-409.

21. Singer M, Deutschman CS, Seymour CW, et al. The ThirdInternational Consensus Definitions for Sepsis and Septic Shock(Sepsis-3). JAMA 2016; 315:801-810.

22. Berrevoets MAH, Ten Oever J, Oerlemans AJM, Kullberg BJ,Hulscher ME, Schouten JA. Quality Indicators for AppropriateOutpatient Parenteral Antimicrobial Therapy in Adults: A SystematicReview and RAND-modified Delphi Procedure. Clin Infect Dis2020; 70:1075-1082.

23. Weiss $E$, Zahar J-R, Lesprit $P$, et al. Elaboration of aconsensual definition of de-escalation allowing a ranking of $\beta$-lactams. Clin Microbiol Infect 2015;21:649.e1-10.

24. Reddel HK, FitzGerald JM, Bateman ED, et al. GINA 2019: afundamental change in asthma management: Treatment of asthma withshort-acting bronchodilators alone is no longer recommended foradults and adolescents. Eur Respir J 2019;53.

25. Chorin E, Padegimas A, Havakuk O, et al. Assessment ofRespiratory Distress by the Roth Score. Clin Cardiol2016; 39:636-639.

26. Lescure F-X, Bouadma L, Nguyen D, et al. Clinical andvirological data of the first cases of COVID-19 in Europe: a caseseries. Lancet Infect Dis 2020;

27. Poses RM, McClish DK, Bekes C, Scott WE, Morley JN. Ego bias,reverse ego bias, and physicians' prognostic. Crit Care Med1991; 19:1533-1539.

28. Fine MJ, Hough LJ, Medsger AR, et al. The hospital admissiondecision for patients with communityacquired pneumonia. Resultsfrom the pneumonia Patient Outcomes Research Team cohort study.Arch Intern Med 1997; 157:36-44.

29. Simonnet A, Chetboun M, Poissy J, et al. High prevalence ofobesity in severe acute respiratory syndrome coronavirus-2(SARS-CoV-2) requiring invasive mechanical ventilation. Obesity(Silver Spring) 2020;

30. Guo W, Li M, Dong Y, et al. Diabetes is a risk factor for theprogression and prognosis of COVID-19. Diabetes Metab Res Rev2020; :e3319.

\section{Supplementary Tables}


entary table1. First round results

haracteristics anddisease course

jry rate

aloxygen saturation

talk without stopping for a breath

ssure

e

nor impaired consciousness

'significant worsening within the last 24 hours.

nthe onset of initial symptoms and admission between 7 days to 10days

dities

’disorder

Relevantand major

Relevantand major

Relevant

Relevant

Noconsensus

Relevant

Relevant

Non-relevant

Noconsensus

Noconsensus

ory failure with continuousoxygen therapy

Threshold:stage III, IV

Noconsensus

Noconsensus

enal failure

Noconsensus

eart failure

Non-relevant

ypertension

Threshold:NYHA III

Non-relevant

sculardisease

Non-relevant

rartery disease

Non-relevant

history of VTE†

Non-relevant

Nonrelevant

a

amunodeficiency Virus (HIV)

Noconsensus

mmunodeficiency

Noconsensus

Noconsensus

sy

itor or ARB

idal anti-inflammatorydrug

Non-relevant

Non-relevant

glucocorticoid therapy

Non-relevant

uppressivedrug

Noconsensus

aditions

riatedwelling

Noconsensus

upport person

Noconsensus

low-up impossible

Noconsensus

Relevant 
entary table2. Second round results

\section{Criteria}

Secondround ruling

haracteristics anddisease course

ory rate

Relevant,major, no consensus on

aloxygen saturation

threshold value

talk without stopping for a breath

Relevant,major, no consensus on threshold value

ssure

Relevant,major, no consensus on threshold value

Relevant,major, no consensus on threshold value

e

nor impaired consciousness

Noconsensus

'significant worsening within the last 24 hours.

Relevant,major

mthe onset of initial symptoms and admission between 7 days

Relevant,major

j

dities

disorder

Non-relevant

Noconsensus

ria: COPD, Respiratory failure with continuous oxygen Validatedas grouped

tsthma

enal failure

eart failure

ria: primary immunodeficiency, uncontrolled

unosuppressive drug, chemotherapy

glucocorticoid therapy

Noconsensus

\section{aditions}

riatedwelling

upport person

Non-relevant

Relevant,threshold: NYHA III

Noconsensus

Non-relevant

low-up impossible

Relevantand minor

Relevantand minor

Relevantand minor 
entarytable 3. Third round results

haracteristics anddisease course

ory rate

Relevant,major, threshold value: $\geq$

aloxygen saturation

talk without stopping for a breath

ssure

25/min

Relevant,major, threshold value: $\leq$

94\%

Relevant,major, threshold value: 8

sec

Relevant,major, threshold value:

$\mathrm{SBP} \leq 90 \mathrm{mmHg}$

e

Relevant,major, threshold value: $\geq$ 120 bpm

nor impaired consciousness

Relevant,major

rsignificant worsening within the last 24 hours.

Relevant,major

mthe onset of initial symptoms and admission between 7 days Non-relevant

s

dities

sisorder

Relevant,minor, threshold value: severe

ria: COPD, Respiratory failure with continuous oxygen Validatedas grouped, minor

tsthma

eart failure

Relevant,minor, threshold: NYHA

III

ria: primary immunodeficiency, uncontrolled

Validatedas grouped, minor

unosuppressive drug, chemotherapy

aditions

riatedwelling

Relevantand minor

upport person

Relevantand minor

low-up impossible

Relevantand minor 